\title{
O processo psicanalítico e a transformação do self
}

\author{
Isabel Mesquita, PhD¹ Rui C. Campos, PhD² \\ Évora, Portugal
}

Pretende-se neste artigo enfatizar que existe uma interligação entre aspetos constitucionais e evolutivos, assumindo que o desenvolvimento possibilita uma constante atualização do self e do mundo relacional e uma expressão madura da vida afetiva. Discute-se a importância dos afetos e das relações precoces na formação das relações de objeto. Defende-se que o processo psicanalítico deverá implicar um desenvolvimento da segurança nos afetos e emoções, a autonomização face às relações de objeto e uma possibilidade de criar novas representações do self que implicam um sentimento de eficácia na regulação do meio, o que permitirá formas de relação de mutualidade e empatia.

Palavras-chave: Sentimento de eficácia; Construção do self; Autonomia face a relações de objeto disfuncionais.

This article intends to emphasize the importance of the interconnections between constitutional and evolutional aspects and the possibility that development allows affective life to find a place of expressivity and a constant actualization of self and of relationships. It will be discussed the importance of affections and early relationships in the formation of object relations. It is also argued that the psychoanalytic process should imply the development of security of affects and emotions, the autonomy from object relations and a possibility to develop new representations of the self which will imply a sense of effectiveness in the regulation of the environment and would allow relationships with empathy and mutuality.

Key Words: Sense of efficacy; Construction of the self; Autonomy from dysfunctional object relations.

English Title: The psychoanalytic process and the enhancement of the self

\section{Cita bibliográfica / Reference citation:}

Mesquita, I. \& Campos, R.C. (2021). O processo psicanalítico e a transformação do self. Clínica e Investigación Relacional, 15 (2): 386-401. [ISSN 1988-2939] [Recuperado de www.ceir.info ] DOI: 10.21110/19882939.2021.150206

\footnotetext{
${ }^{1}$ Professora Auxiliar, no Departamento de Psicologia da Universidade de Évora, com doutoramento em Psicologia Clínica, Psicóloga Especialista em Psicologia clínica e em Psicoterapia pela OPP com o grau de Psicanalista Titular da Ap - Associação Portuguesa de Psicanálise e Psicoterapia Psicanalítica. A correspondência relativa a este artigo deverá ser enviada para:mesqui@uevora.pt, phone: +351962840616 ou para Universidade de Évora, Apartado 94, Évora 7002-554, Portugal.

${ }^{2}$ Professor Auxiliar com Agregação, com Doutoramento em Psicologia Clínica no Departamento de Psicologia da Universidade de Évora. Psicólogo Especialista em Psicologia clínica pela OPP.
} 
Nas teorias psicanalíticas, como no desenvolvimento humano, a mudança é necessária: o passado importa, o presente é tido em conta, e a criação do futuro é pertinente. A estagnação do desenvolvimento é sempre fator patogénico e patológico: gerador de doença e insatisfação e, ao mesmo tempo, revelador dessa patologia.

Temos assistido a um incremento de novas teorias psicanalíticas, construídas em parte sob outras já existentes, como as interpessoais (Sullivan, 1953), da relação de objeto (Fairbairn, 1952; Klein, 1988; Winnicott, 1945, 1952, 1960, 1965, 1971a, 1971b) e da Psicologia do Self (Kohut, 1971, 1977). Estas novas perspetivas englobam o American Middle Group (Spezzano, 1997), onde a teoria contextualista de Stolorow et al, (1992, 1994, 2002, 2004), a relacional (Mitchell, 1988, 1999, 2002) ou a dos sistemas diádicos (Beebe, Jafee, \& Lachmann, 1992), ocupam um lugar central, apresentando-se como perspetivas alternativas e dominando o cenário da psicoterapia americana.

Algumas destas novas perspetivas enfatizam a fenomenologia da experiência vivida consciente (Milles, 2005) e a sintonia indivíduo-outro, relegando muitas vezes os aspetos inconscientes para um plano secundário ou abolindo mesmo o intrapsíquico. Deste modo, em muitas destas novas teorias psicanalíticas prioriza-se o que se conhece (epistemologia) face ao que se é (ontologia) (Frederikson, 2000, 2003, 2005).

Neste artigo pretende-se acentuar a ideia de que a experiência e, o modo como ela é organizada e vivida, estão diretamente ligados ao biológico e ao intrapsíquico, mas, igualmente, ao interpessoal e ao contextual, todos, em última instância constitutivos dessa experiência e responsáveis pelo desenvolvimento mental. Enfatiza-se, neste trabalho, a importância de no processo psicoterapêutico haver espaço para analisar o efeito das relações do passado no presente e na construção do futuro, de forma a possibilitar uma autonomia face a relações de objeto disfuncionais e, permitir a construção de uma representação mais positiva do self rumo à sua transcendência, leia-se autonomia e desenvolvimento.

Partimos da ideia que o ser humano é agente e reagente, estando o seu self no centro da sua experiência relacional, sendo construído e, ao mesmo tempo, construindo a experiência rumo ao "seu desenvolvimento" através da sua atualização contínua (Rogers, 1951). As diferentes relações ao longo da vida podem constranger ou facilitar esse processo de desenvolvimento tendo em consideração a competência de cada um para o uso dos objetos (Winnicott, 1971b). Convém salientar, no entanto, que os aspetos biológicos / pulsionais não podem ser descartados. Thomas e Chess (1977) referiram-se às diferenças temperamentais existentes à nascença e mantidas ao longo de toda a vida, reveladoras do idioma pessoal 
(Bollas, 1989). Em pacientes onde existem falhas ao nível da simbolização dos afetos, por exemplo, a importância destes aspetos temperamentais é, aliás, evidente.

Consideramos que o self está orientado para o desenvolvimento (Bollas, 1983, 1989; Kohut, 1977; Winnicott, 1965) e para uma constante atualização (Maslow, 1954; Perls 1973; Rogers, 1951;). A necessidade de se "tornar o próprio" é assim o principal motivador da mente humana (Bollas, 1989). Saliente-se, contudo, que este tornar-se no que se é não diz respeito a uma atualização no sentido do modelo biogenético, tem antes a ver com a possibilidade de entender as expressões inconscientes e a simbolização da experiência e, ir desenvolvendo o seu self em consonância. O desenvolvimento implica que haja uma expansão do self e a criação de uma coerência interna, de forma a conseguir uma flexibilidade adaptativa com potencial criador.

O ser humano forma-se e desenvolve-se a partir de experiências de relação, mas também de experiências de separação (Blatt \& Bass, 1992, 1996), sendo estas últimas tão são essenciais ao processo de desenvolvimento do self como as primeiras. Em boa verdade, a identidade "emerge através de uma dialéctica... entre o Self... [percebido como] separado e o self experienciado na sua vinculação aos objetos" (Blatt \& Blass, 1996, p. 316).

As relações de objeto são centrais para a experiência do self, possibilitando uma antecipação securizante da mesma. Uma vez ativadas, essas estruturas, compostas por afetos, cognições e motivações, constituem-se como princípios organizadores que vão definindo as nossas modalidades relacionais. Contudo, consideramos que a não separação/autonomização face a relações de objeto às quais se associam representações do self frágeis e desvalidas, conduzem à estagnação do processo de desenvolvimento e impedem o surgimento de visões mais saudáveis do self. Pode considerar-se mesmo, que as várias formas de psicopatologia implicam distorções nas representações objectais e do Self e resultam de experiências desenvolvimentais traumáticas, geradoras de insegurança e de sentimentos de menor valia. Pelo contrário, vinculações seguras na infância contribuem para a construção de representações progressivamente mais evoluídos (Blatt, 2008; Blatt, Besser, \& Ford, 2007) que guiam o comportamento e a vida relacional.

Neste sentido, a prática da psicoterapia psicanalítica e da psicanálise deve centrar-se na possibilidade de desenvolvimento das potencialidades do self que conduzirão à autonomização face a representações objetais disfuncionais, de modo a possibilitar o alargamento da experiência, por oposição à vivência defensiva que conduz à acomodação patológica (Brandchaft, Doctors, \& Sorter, 2010) e ao evitamento da re-traumatização (Bromberg, 2003, Mesquita, 2016) no futuro. 
A experiência psicoterapêutica deve possibilitar a criação de um espaço psicológico em que seja possível experimentar novas potencialidades, promovendo a autonomização e a separação face a relações de objeto internas geradoras de padrões repetitivos e bloqueadores do alargamento da experiência. No entanto, é sempre preciso ter em conta que, como refere Lachmann (2007), a disponibilidade da pessoa para se permitir ser empaticamente compreendida pelo analista, como importa também o seu poder criativo e o seu potencial de transformação. De modo semelhante, é importante a motivação de cada um para se desenvolver (Greenberg, Rice, \& Elliott, 1993; Perls, 1973; Rogers, 1951) e a sua capacidade de uso do objeto (Winnicott, 1965, 1971), no sentido da capacidade que cada um tem para se constituir como agente no meio e usar a relação com o outro para se poder transformar. Ao longo do processo terapêutico espera-se que o paciente se possa ir apropriado de aspetos significativos da relação terapêutica, o que lhe permite ir revendo o seu sentido do Self e ir-se relacionando com o terapeuta de forma cada vez mais evoluída (Blatt, Auerbach, \& Behrends, 2008), sendo que estas aquisições devem ir sendo progressivamente transferidas para o espaço externo ao processo terapêutico.

\section{A formação da vida mental e a sua perturbação}

Devido à sua in-finalização o ser humano é um mistério. Estamos em permanente desenvolvimento e adoecemos quando essa possibilidade encripta. A preocupação com o desenvolvimento e com o futuro gera conflito e faz surgir o sintoma.

Concebemos a vida mental, num sentido monádico, diádico e extra diádico, isto é, como resultado da interação entre a dotação genética / biológica, por um lado, composta por disposições afetivas inatas (Ekman \& Friesen, 1975; Izard, 1977; Tomkins, 1962), inicialmente geradoras de estados pré-subjetivos (Benjamin, 1999) e, por outro lado, um meio facilitador do desenvolvimento das potencialidades do self; mas tendo também em consideração a capacidade para o uso do objeto (Winnicott, 1965, 1971; Summers, 2013a, 2013b) como experiência transformadora (no sentido de Bollas, 1989) - ou seja o modo como cada um vai aproveitando o que lhe é oferecido para se poder transformar.

Assim, os nossos processos adaptativos vão-se construindo e configurando (no sentido em que se podem expandir ou inibir) a partir das experiências vividas, em que somos agentes e participantes. Há sempre a possibilidade de aproveitar os diversos contextos relacionais por onde o percurso desenvolvimental decorre. Bowlby (1969/1982) já havia referido duas motivações adaptativas básicas inerentes ao processo de desenvolvimento: a motivação para a relação e vinculação e a motivação para a exploração e gestão do meio. 
Claro está que no inicio da formação da vida mental se está mais dependente da interação com uma mente mais desenvolvida, com a sua função alfa (Bion, 1961), com capacidade de sintonia (Stern, 1985), enfim, com um meio suficientemente bom que reconheça e responda aos afetos e emoções, mas que também possibilite um espaço de génese, ou seja um espaço lúdico, aberto e não constrangedor ou ansiogénico. Este espaço vai possibilitando à criança a perceção de poder usar a resposta materna para começar a gerir ela própria as suas emoções e as sensações mais negativas / desprazerosas, no sentido de desenvolver um sentimento de eficiência, sobre si própria e sobre o meio. No cerne do self relacional está um sentimento de competência de auto-regulação e hétero-regulação (regulação do meio).

Inicialmente, é a partir de uma nova perspetiva revelada na reação da mãe aos estados afetivos da criança que é possível a esta ir criando novas estratégias reguladoras, desenvolvendo-se um sentimento de eficácia/agência, tão importante para o desenvolvimento do sentimento de segurança do Self (Stern, 1985, 2004; Demos, 1989,1992, Mesquita, 2013). Salientando a importância da ação, também Stern (1985), Beebe e Lachmann (1992, 2002) e Benjamin (1995) destacam o sentimento de eficácia emergente do sentimento de ter efeito sobre o meio relacional (Aron, 1996) o que tem consequências para o desenvolvimento do Self. Inicialmente, é necessário um cuidador que seja capaz de identificar o afeto e que possibilite uma resposta que não se encerre em si mesma, mas que facilite a criação de significado e que seja potenciadora de novas respostas criadoras e propulsoras do desenvolvimento do self.

Uma representação positiva do self estará dependente deste sentimento de eficácia sobre o meio e da possibilidade de confiar nas emoções do próprio, porque o sujeito as pode manejar. Como consequência disso, essas emoções não são vividas com desconfiança. Claro está também, que essa representação positiva do self dependente da qualidade da experiência relacional. Já Piaget (1981) havia referido que a criança repetia várias ações no sentido de ter efeito sobre o meio; essa repetição vai desenvolvendo um sentimento de autoeficácia, potenciador da autoestima e de uma representação saudável de si.

Contudo, quando o meio relacional se apresenta como menos facilitador ou até mesmo como constrangedor do desenvolvimento do self, porque conduz à anulação ou mesmo à invalidação de alguns afetos e, se a criatividade ou a tendência expancionista do self bloquear, fica congelada toda a possibilidade de expansão do self e está aberto o caminho da repetição e, consequentemente, da estagnação e da doença. Sabemos que quando existem aspetos que ficam sem possibilidade de ligação ao simbólico, eles apenas se organizam sob a forma de procedimento/comportamento. 
Neste sentido, podemos assim ver o sintoma, não como o retorno do recalcado, mas como indicador da impossibilidade do self se poder revelar na sua essência. Bollas (1989) referira como principal motivador da experiência humana a necessidade de se tornar genuíno. Também Rogers (1951) já havia referido que quando existe uma discrepância entre o conceito de selfe a experiência, a ansiedade é espoletada. Esta mesma ideia é reforçada por Bromberg (2003), que refere que a experiência traumática está ligada à descontinuidade da experiência do self.

Importa fazer aqui um parêntese na medida em não estamos a falar de um self verdadeiro no sentido winnicottiano ou kohutiano, porque esse parece remeter para algo estático, com um design pré-programado e não transformável pela relação, que se revelaria em face de um ambiente facilitador ou na presença de objetos do self competentes na sua função. Referimo-nos a um self genuíno que diz respeito à possibilidade de se impor/expressar numa relação de mutualidade; a possibilidade de ser como se é, sempre aberto à transformação benéfica pela relação e não à modelagem nociva. Portanto, no sentido de se ser congruente com o mundo emocional e cognitivo do próprio e com consciência da gestão das suas emoções e estados afetivos, numa interação recíproca com o meio. Neste sentido, o que se pode encontrar no inconsciente são estes afetos sob a forma de potencialidades que não encontraram um lugar de expressividade no contexto relacional que se expressaram, mas tiveram de se anular ou, que nunca tiveram possibilidade de expressão (Mesquita, 2016).

Assim, consideramos que as modalidades defensivas que se desenvolvem para permitir uma adaptação à negligência afetiva ou à sobreproteção não se constituem como criações de significado; possibilitam a adaptação, mas não a significação (Greenberg, Rice, \& Elliott, 1993). E sabemos também que, quanto mais dolorosa a experiência, maior a necessidade de dissociação (Bromberg, 1998), mais rigidificado fica o sistema mental e, consequentemente, menos abertura existe ao interpessoal e menor o proveito da intersubjetividade. Nestes casos, todos os esforços do indivíduo vão no sentido da proteção do self, do seu delineamento e coesão, e não no sentido da sua expansão através da interação com o outro.

Ainda que o nosso sistema emocional tenha naturalmente uma tendência para preservar a continuidade das relações (Bromberg, 2003), nas situações patológicas e de grande sofrimento, essa tendência é maior, porque a segurança interna e relacional é menor, sendo um terreno fértil para a frustração, a desilusão de amor e o adoecer mental.

Nesta linha, a psicanálise e a psicoterapia psicanalítica devem ter em consideração a agência do sujeito sobre o meio e do sujeito enquanto organizador da sua experiência e possuidor de potencial transformador. Neste sentido, considera-se importante que no processo analítico se analise o modo como o contexto foi condicionando inicialmente o desenvolvimento e, 
aquilo que se manteve não transformado e, por conseguinte, alienado da experiência. Interessa o modo como a pessoa foi elaborando a sua história, quais os afetos que a dominaram, quais os que se mantiveram num estado embrionário e sem possibilidade de expressão e, muito em particular, aquilo que é possível vir a desenvolver-se. Importa também que o paciente possa compreender o modo como a relação de objeto tem condicionado as suas modalidades relacionais e a sua confiança enquanto agente no meio, para que possa experimentar novas formas de ser e de ter efeito sobre o meio.

\section{Aspetos fundamentais no processo psicanalítico}

As novas perspetivas psicanalíticas como por exemplo a de Frank Summers (2005, 2012, 2013), ou até mesmo a de Mitchell (1988), apontam para uma necessidade de mudanças no modo de estar e de entender do psicanalista. Se é necessária uma postura contentora (Bion, 1961) de holding (Winnnicott, 1965) e empática (Kohut, 1977), também é necessária uma atitude mais interventiva, no sentido de facilitar o emergir de novas formas de experiência do self e de novas modalidades de relacionar nos pacientes.

Do que se referiu anteriormente, destaca-se a importância de promover a agência do paciente, no sentido de ser uma parte vital no processo de auto-sintonia emocional e de transcendência do self. Assim, o processo psicanalítico / psicoterapêutico não pode incidir só sobre o que aconteceu a cada um no passado (Frederikson, 2003), porque o passado não pode ter uma governação impessoal sobre o presente e/ou o futuro. Se quisermos, na linha de Frederikson (2000, 2003) e Summers (2013a, 2013b), eu sou o que sou agora e aquilo que não fui, mas posso vir a ser. É esta descoberta, esta novidade, este desenvolvimento que o processo analítico enquanto psicoterapêutico deve promover.

Um dos aspetos principais da experiência psicanalítica deverá ser a recaptura progressiva da experiência do self que está alienada e, como tal, distante do discurso pessoal e interpessoal, possibilitando ao analisando a descoberta continua de quem é, e do que quer vir a ser, numa possibilidade crescente de dialogo intra e interpessoal. Num olhar complementar, pode considerar-se que a evolução da pessoa no contexto analítico envolverá, muito provavelmente, uma reativação do processo de desenvolvimento e que, o contexto terapêutico permitirá, porventura, a criação das condições para que as experiências interpessoais entre analista e cliente aí ocorridas contribuam para uma revisão do sentido do Self, o que vai possibilitar expressões mais evoluídas de relacionamento interpessoal, as quais, por sua vez, poderão contribuir para uma reedificação mais madura do Self (Blatt, 2008; Blatt \& Luyten, 2009). 
Interessa compreender e clarificar o que a pessoa tem feito com o que lhe fizeram e como é que isso condiciona o seu futuro, mantendo sempre a ideia de que o sujeito também é determinado por aquilo que ele próprio vai fazendo no seu presente e relativamente ao seu futuro (Summers, 2013a, 2013b). Sabemos que a repetição de padrões relacionais interiorizados desde a infância é um fator limitador da experiência e, como tal, condicionante do desenvolvimento.

Deste modo, o processo analítico não deve promover um "eclipse" da pessoa, antes deve colocá-la no centro da sua ação, como reagente, mas também, e sobretudo, como agente no seu contexto relacional. Na verdade, se formos somente produtos de um contexto não se pode falar de intersubjetividade (Frederikson, 2000, 2003). Então, defendemos que o self é constantemente atualizado na relação, mas não é determinado pela relação; é coconstruído, no sentido em que resulta do que o indivíduo pode e retira de cada relação significativa que estabelece. A relação cria as condições necessárias, mas não suficientes para que o desenvolvimento do self ocorra. Estes mesmos mecanismos têm lugar ao longo do processo psicoterapêutico.

O processo psicoterapêutico implicará em primeiro lugar uma experiência de espelhamento contentora. Não no sentido de espelhamento da imagem grandiosa do paciente como referia Kohut $(1971,1977)$, mas sim no sentido de o analista ser nomeador e contentor das emoções do paciente. Esta postura do analista vai permitir que o paciente possa olhar-se emocionalmente, olhar para a sua emoção. Deste modo, é possível passar de o que sente (sintoma) para o como se sente (afeto), no sentido de se formar um auto compromisso afetivo - a visão do próprio como construída e moldada por experiências de interação, afeto e emoção (Mesquita, 2016). Este aspeto é importante para que se possa desenvolver um sentimento de confiança nas emoções (Demos, 1984, 1988), de modo a que estas não sejam vividas como ameaçadoras para o próprio, nos casos de maior desorganização do self, ameaçadoras para a relação com o outro ou geradoras do sentimento de rejeição - nos casos de defeito no self em que a desorganização do self é mais ligeira. Neste processo está implicado um incremento da capacidade de resistência à frustração (Bion, 1961) que habilita o sujeito na gestão de afetos e emoções desprazerosos, o que possibilita, por sua vez, o uso da criatividade na gestão de circunstâncias de vida menos favoráveis às quais se possa estar propenso. Se, no entanto, esta confiança nos afetos não existir, estes não se podem constituir como condutores de ações, ficando inibidos / bloqueados.

Os afetos e emoções que não encontraram ainda um meio para se afirmar necessitam do reconhecimento por parte do analista para que possam ser sentidos como reais e constituintes da experiência pessoal. À semelhança do que se passa nos primeiros estados 
de desenvolvimento, o bebé, ainda que possua de forma inata certos afetos, necessita que outra pessoa os reconheça para que possam ser sentidos como reais (Beebe \& Lachmann, 1992), passando a estar inseridos na sua experiência emocional. Caso contrário, serão sentidos como defeituosos ou ilegítimos, pelo que serão inibidos ou colocados fora sob a forma de comportamento ou sintoma. Assim, é a possibilidade de revelação desses afetos que ainda não haviam tido possibilidade de encontrar uma configuração relacional de expressividade (Mesquita, 2017b) que fortalece a relação paciente-analista, relação essa que se constitui como o lugar do possível e que permite viabilizar e potenciar o desenvolvimento do self.

O analista sente com o paciente, mas não sente como ele, o que se declara como uma nova perspetiva. A contenção emocional aporta consigo uma nova resposta a emoções que passam a poder ser vividas com menor potencial ameaçador, sendo cada vez mais possível a sua integração e recolocação no sistema emocional. A crescente suportabilidade da dor emocional abre espaço ao alívio do self e à representação de um self com experimentação psicológica.

Neste seguimento, é possível ao analista inaugurar o espaço para as interpretações evocativas, que facilitam o emergir da narrativa e do navegar pela história relacional. Claro está que, genericamente, a interpretação ocorre ao longo de todo o processo analítico e, num certo sentido, ela própria promove a relação terapêutica e a proximidade psicoterapeuta / analista - paciente. A interpretação, se precisa, no timing certo e ajustada ao paciente pode ser sentida pelo último como uma expressão de entendimento e interesse da parte do terapeuta (Modell, 1976). Uma interpretação precisa traz ao paciente o sentir que é capaz de entrar e contacto com o outro, que é capaz de comunicar e que as suas experiências internas e sentimentos tem coerência e podem ser compreendidas e aceites por outra pessoa (e.g., Fonagy \& Target, 2005). Assim a interpretação é já reveladora de uma nova relação, entre analisando e analista.

O paciente pode ir então começando a desbravar um olhar reflexivo para o(s) processo(s) que conduziram ao seu sentir e à representação de si; há espaço para se poderem realizar interpretações correlacionais, que estabelecem uma ligação entre o afeto, a emoção, a representação do self e a experiência relacional. Este caminho, que não visa uma culpabilização dos objetos, mas que pretende entender a virulência das relações de objeto internas; constitui-se como uma oportunidade para começar a refletir sobre o processo interacional, rumando em direção ao conhecido não pensado (Bollas, 1989).

A compreensão do efeito relacional do passado sobre a forma como o sujeito se construiu possibilita um aumento do sentimento de competência na gerência desse mesmo efeito. $O$ 
analisando vai-se tornando cada vez mais um sujeito ativo, autor da sua vida e desligandose de uma visão de reagente à sua história de contexto relacional. Ao longo do processo analítico é possível ir recolocando emocionalmente o passado, de modo a que este deixe de condicionar o presente e o futuro e, que seja possível progredir na transcendência do self.

É neste movimento compassado em que o sujeito se vê e, começa a compreender o modo como se vê, que é possível ir alterando a forma como se vê. Pode então ocorrer a autonomização em relação aos objetos internos, porque a representação de si começa a mudar e, consequentemente, muda a relação com esses objetos internos, mas também externos, uma vez que uma representação mais válida do self associada a um sentimento de ter efeito sobre o meio, implica um sentimento de gestão das circunstâncias, tornando possivel passar de reagente a agente. Novas formas de ser levam a novas formas de se relacionar, sendo o inverso também verdadeiro. Esta dialética entre a definição de si e o mundo relacional está agora mais em conformidade e deixa de ser geradora de conflito.

Como sabemos, as pessoas tendem a enquadrar a experiência em padrões relacionais préexistentes, padrões que são geralmente impeditivos da perceção de novas perspetivas (Bollas, 1989; Strenger, 1998). É necessário a autonomização face a relações de objeto internas disfuncionais, que se constituíram como organizadores da experiência, para que possam emergir novas conceções sobre o self e sobre os relacionamentos interpessoais. Isto para que em seguida se possam abrir novas perspetivas de auto gerenciação e para que se inicie um novo processo de experimentação. O processo terapêutico deverá permitir uma progressiva eliminação das representações mentais disfuncionais e o desenvolvimento de novas representações, mais articuladas, diferenciadas e integradas acerca do Self, dos outros e das relações (Blatt \& Luyten, 2009). Terá também como função essencial o desbloquear das potencialidades do self (Summers, 2013a, 2013b), que ainda não encontraram um meio facilitador para se poderem revelar, configurar e desenvolver. Falamos da existência de partes do self que estavam alienadas e não desenvolvidas, uma vez que não entravam de forma autêntica no espaço interpessoal/relacional.

Mas é preciso também que o paciente experimente, que possa ir "lá fora", fora da relação com o analista e teste as novas potencialidades do seu self, que possa experimentar regular o meio e autorregular-se. Não se pretende apenas desenvolver as competências de insight, reflexivas e de mentalização, mas abrir caminho para a possibilidade de novas experiências relacionais e de ação no meio. É necessário que ocorra uma internalização ativa, construtiva e co-criada, filtrada pelo self, da nova experiência relacional, que ao longo do processo terapêutico ocorre essencialmente da mesma forma que no desenvolvimento normativo: através de uma espiral progressiva de envolvimento gratificante com o objeto e de 
experiência de incompatibilidade, de relacionamentos e de momentos de separação, numa relação privilegiada (Blatt et al., 2008). Há então no processo psicoterapêutico esse tempo de ir e voltar ao espaço analítico; o paciente experimenta novas formas de ser e de se relacionar e, precisa ainda de vir buscar confirmação/validação sobre a sua nova forma de ser, estar e se relacionar. Reapresenta-se, mas necessita ainda desta dupla confirmação - do analista e do meio interacional.

Este processo de abertura a novas realidades, a novas formas do self se revelar e a novas modalidades relacionais aportam ainda angústias de perda de ligação a objetos internos e a objetos reais e, consequentemente, ameaças de perda de um self já conhecido, de perda do sentimento de ser desta forma, às vezes quase petrificada, mas que é conhecida e aporta segurança, ainda que frágil. Daqui decorre também a necessidade de o analista ter uma empatia analítica transcendente (Summers, 2013), e não apenas uma empatia com as emoções contagiantes e com o que as motivou. A empatia que permite entender o que o paciente é e, o que não tem sido; é uma forma de empatia que possibilita intuir sobre o que o self do paciente necessita realizar e, que potencialidades permitirão a expansão desse self - o que pode vir a ser. $\mathrm{O}$ analista é, num certo sentido, um visionário, na medida em que antecipa o que o paciente pode desenvolver e o que pode vir a ser, sem, no entanto, impor isso ao analisando.

Que "a ação psicoterapêutica desperte: o fascínio... pelo novo, pelo que ainda não foi mas pode vir a ser - a indagação permanente.... um olhar centrado no futuro; o passado, esse, é para ser integrado [para ser compreendido], como guia-farol, que ilumina o que pode vir, em busca de outras terras, do desconhecido, que mostra onde há mar livre para navegar..." (Campos, 2016, p. 46).

\section{Conclusão}

Consideramos que a felicidade está ligada à possibilidade de nos irmos desenvolvendo, do self se ir transcendendo, de irmos construindo novas narrativas e reconstruções da nossa história, inseridas numa espiral criativa que nos faz avançar e expandir. Porque à medida que nos desenvolvemos vamos modificando a experiência relacional; à medida que as necessidades do selfse modificam, modificam-se as relações de objeto internas e as relações interpessoais. Assim, é a possibilidade de se ir construindo novos significados pessoais que potenciem novas experiências relacionais, que constitui o substrato da vida, sempre intrincada na fluidez do desejo - numa permanente tensão dialética e criadora, entre o que se é, e como se está com o outro. 
Se este é o propósito da vida - a transcendência do self - é o propósito da análise também; a possibilidade de numa nova relação, de compromisso, seriedade e dedicação se desenvolverem formas auto-sintónicas de ser e de se relacionar.

A evocação de novas experiências de objeto (Cooper \& Levit, 1998) é uma das possibilidades no processo analítico que, experiências que decorrem de novas formas de ver e sentir o self de forma autêntica. Assim, defendemos que a experiência do self e uma progressiva mudança na sua representação é um aspeto essencial do processo analítico, para que se possa ir sempre no caminho do desenvolvimento e da transcendência. A representação do self, mesmo que frágil ou defeituosa está sempre ligada a representações da relção com os objetos. Logo, o trabalho de autonomização face aos objetos internos e a possibilidade de os olhar e representar de uma outra forma, apresenta-se como essencial no trabalho analítico. Esta autonomização / separação aporta muitas vezes o sentimento de não self, de não estar em ligação, conduzindo a impasses no processo analítico, pelo que deve ser manejada de forma cuidadosa.

A relação com o analista não é só por si suficiente para promover esta autonomização sem que o paciente alcance, nesta nova relação, o sentimento de competência e efeito sobre o meio relacional. Pretende-se que o paciente adquira a segurança de que pode modificar o meio e geri-lo beneficamente, de forma a não ter de evita-lo, por este se apresentar como assustador, ou de se submeter a ele porque o vivencia como dominador.

Deste modo, não consideramos que se trate propriamente de uma internalização "passiva" e tout court da relação com o analista, mas a possibilidade de nesta relação ocorreram transformações decorrentes do uso criativo que o paciente faz do espaço co- construído nesta relação a dois. Diríamos que se trata de uma internalização criativa, modificada pelo desejo do paciente, pelas suas expectativas e fantasias, pelo seu mundo interno e pela capacidade de fazer uso daquilo que lhe é "disponibilizado" pelo outro.

O processo de transcendência do self implica o reconhecimento do inconsciente como dinâmico, não na linha de Freud que o via como a necessidade de descarga pulsional (Freud, 1915), mas dinâmico porque implica um movimento da experiência afetiva que pretende a realização, a renovação e a transcendência - ir para além do que se tem sido.

O espaço analítico é na linha de Summers (2013a, 2013b) um espaço transicional, aberto à criação e a novas formas de se poder ser e relacionar, embora se deva ter em linha de conta com as disposições afetivas inatas e as diferentes potencialidades de cada um. O espaço analítico deverá em princípio pretender o desabrochar do que está por detrás da estrutura defensiva que se foi edificando ao longo do desenvolvimento e que o bloqueou / desviou / comprometeu. Assim, o processo analítico deve ter em conta o que está em germinação em 
cada um; o terapeuta / analista enquanto auxiliador e facilitador, mas contando sempre com a motivação para o desenvolvimento, Rogers (1951), diferente em cada um.

\section{Resumen}

En este artículo se pretende enfatizar que existe una interconexión entre los aspectos constitucionales y evolutivos, asumiendo que el desarrollo posibilita una actualización constante del yo y del mundo relacional y una expresión madura de la vida afectiva. Se discute la importancia de los afectos y las relaciones tempranas en la formación de las relaciones de objeto. Se argumenta que el proceso psicoanalítico debe implicar un desarrollo de seguridad en afectos y emociones, autonomía en relación a las relaciones de objeto y posibilidad de crear nuevas representaciones del yo que impliquen un sentido de efectividad en la regulación del entorno, lo que permitirá relación de reciprocidad y empatía.

Palabras clave: Sensación de efectividad; Autoconstrucción; Autonomía de las relaciones de objeto disfuncionales.

\section{REFERÊNCIAS}

Aron, L. (1996). A meeting of minds. Hillsdale, NJ: Analytic Press.

Beebe, B., Jafee, J., \& Lachmann, F. (1992). A dyadic system view of communication. In N. Skolnick, \& S. Warchaw (Eds.,) Relational perspectives in Psychoanalysis (pp. 61-82). Hillsdale, NJ: Analytic Press.

Beebe, B. \& Lachmann, F. (2002). Infant Research and Adult Treatment: Co-Constructing Interactions. Hillsdale, NJ: The Analytic Press.

Benjamin, J. (1992), Recognition and Destrution. A outline of intersubjectivity. In N. Skolnick \& S. Warshaw (Eds), Relational perspectives in psychoanalysis (pp. 43-60). Hillsdale, NJ: The Analytic Press.

Benjamin, J. (1995). Like subjects, love objects. New Haven, CT: Yale University Press.

Benjamin, J. (1997). Shadow of the other. New York: Routledge.

Bion, W. (1961/1988). A Theory of thinking. In : E. Spillius (eds)., Melanie KleinToday (vol.1) (pp. 178186). London: Routledge.

Blatt, S. J. (2008). Polarities of experience: Relatedness and self-definition in personality development, psychopathology, and the therapeutic process. Washington, DC: American Psychological Association Press.

Blatt, S. J., Auerbach, J. S., \& Behrends, R. S. (2008). Changes in the representation of self and significant others in the treatment process: Links between representation, internalization, and mentalization. In Jurist, E. L., Slade, A., \& Bergner, S. (Eds), Mind to mind: Infant research, neuroscience, and psychoanalysis (pp. 225-263). New York, NY: Other Press. 
Blatt, S., Besser, A., \& Ford, R. (2007). Two primary configurations of psychopathology and change in thought disorder in long-term, intensive, inpatient treatment of seriously disturbed young adults. American Journal of Psychiatry, 164, 1561-1567.

Blatt, S. J., \& Blass, R. B. (1996). Relatedness and self-definition: A dialectic model of personality development. In G. G. Noam, \& K. W. Fischer (Eds.), Development and vulnerabilities in close relationships (pp. 309-338). Hillsdale, New Jersey: Erlbaum.

Blatt, S., \& Luyten, P. (2009). A structural-developmental psychodynamic approach to psychopathology: Two polarities of experience across the life span. Development and Psychopathology, 21, 793-814.

Bollas, C. (1987). The shadow of the object. London: Free Associations.

Bollas, C. (1989). Forces of destiny. London: Free Associations.

Brandchaft, B.; Doctors, S.; \& Sorter, D. (2010) Toward an emancipatory Psychoanalysis. Branchaft's Intersubjective Vision. N.Y. Routledge: Taylor \& Francis Group.

Bromberg, P. (2003). Something wicked this way comes. Trauma, dissociation, and conflict: The space where psychoanalysis, cognitive science, and neuroscience overlap. Psychoanalytic, 3, 558574 .

Campos, R. C. (2016). Comentário à Conferência: "Amor à vida", por António Coimbra de Matos. In I. Mesquita (Org), Actas do Encontro com (o) amor: Percursos, expressões e desenvolvimento (pp. 4547). Évora: Departamento de Psicologia, ECS, Universidade de Évora.

Cooper, S.\& Levit, D. (1998). Old and New Objects in Fairbairnian and American Relational Theory, In: L. Aron \& A. Harris Ed. Relational Psychoanalysis: Innovation and Expansion (pp. 51-74), London: Analytic Press.

Demos, V. (1989). Affect and the development of the self: a new frontier. In: A. Goldberg (Ed.), Frontiers in self psychology: Progress in self psychology (pp. 27-53), Hillsdale, NJ: The Analytic Press.

Demos, V. (1992). The early organization of the psyche. In: J. Barron, M. Eagle \& D. Wolitzky (Eds.), Interface of psychoanalysis and psychology (pp. 200-233) Washington, DC: The American Psychological Association.

Ekman, P. \& Friesen, W. (1975). Unmasking the face. New Jersey: Prentice Hall.

Fairbairn, W. R. D. (1952), Psychoanalytic studies of the personality. London: Tavistock.

Fonagy, P., \& Target, M. (2005). Some reflections on the therapeutic action of psychoanalytic therapy. In J. S. Auerbach, K. N. Levy, \& C. E. Schaffer (Eds.), Relatedness, self-definition, and mental representation: Essays in honour of Sidney J. Blatt (pp. 191-212). London: Routledge.

Frederickson, J. (2000). There's something "youey" about you. Contemporary Psychoanalysis, 36, 587-617.

Frederickson, J. (2003). The Eclipse of the Person in Psychoanalysis. In: Understanding Experience: Psychotherapy and Postmodernism, ed. Roger Frie. London: Routledge. 
Frederickson, J. (2005). The problem of Relationality. In: John Milles (Ed). Relational and Intersubjective perspectives in Psychoanalysis: a critique, (pp.71-96). USA: Jason Aronson.

Freud, S. (1915). Instincts and their vicissitudes., Standard Edition,14, pp.117-140.

Greenberg, L.; Rice, L. \& Elliott, R. (1993). Facilitating Emotional Change: The Moment by Moment Process. NY: Guilford Press.

Guisinger, S., \& Blatt, S. J. (1994). Individuality and relatedness: Evolution of a fundamental dialectic. American Psychologist, 49, 104-111.

Izard, C. E. (1977). Human Emotions. New York: Plenum Press.

Kernberg, O. (1976). Object relations theory and clinical psychoanalysis. New York: Jason Aronson.

Kohut, H. (1971). The analysis of the self. New York: International Universities Press.

Kohut, H. (1977). The restoration of the self. New York: International Universities Press.

Mesquita, I. (2013). Disfarces de Amor: sobre os relacionamentos amorosos e a vulnerabilidade narcísica. Lisboa: Climepsi Ed.

Mesquita, I. (2016). O trauma sob controlo: uma perspetiva relacional acerca do trauma, das relações e da violência familiar. Revista Portuguesa de Psicanálise e Psicoterapia Psicanalítica, 5, 20-28.

Mesquita, I. (2016). Conferencia "Vim dali, mas passei por aqui e vou a caminho: sobre o processo psicanalítico e a transcendência do self". Conferência proferida na Associação portuguesa de Psicanalise e Psicoterapia Psicanalítica, Fevereiro, 2017.

Mesquita, I. (2017b). Relacionamentos amorosos como experiências de ser e de não ser.

Uma leitura psicanalítica da função no Self do relacionar amoroso e da repetição. Trabalho apresentado à Associação portuguesa de psicanalise e psicoterapia psicanalítica para aquisição de titulo de membro titular. Abril, 2017.

Mitchell, S. A. (1988). Relational concepts in psychoanalysis: integration. Cambridge, MA: Harvard University Press.

Mitchell, S. A. (1992). True selves, false serves, and the ambiguity of authenticity. In N. J. Skolnick \& S. C. Warshaw (Eds.), Relational Perspectives in Psychoanalysis, (pp. 1-20). Hillsdale, NJ: Analytic Press.

Mitchell, S. A. (2002). Relationality: From attachment to intersubjectivity. Hillsdale, NJ: Analytic Press.

Mitchell, S., \& Aron, L. (1999). Relational Psychoanalysis: The Emergence of a Tradition. Hillsdale, NJ: Analytic Press.

Modell, A. H. (1976). The holding environment and the therapeutic action of psychoanalysis. Journal of the American Psychoanalytic Association, 24, 285-308.

Piaget, J. (1981). Intelligence and affectivity: Their relationship during child development. T. A. Brown \& C. E. Kaegi (Eds \&trans.). Palo Alto, CA: Annual Rewiews.

Schore, A. (2003a). Affect dysregulation and disorders of the self. New York: W. W. Norton.

Spezzano, C. (1977). The emergence of an American middle school of psychoanalysis. Psychoanalytic Dialogues, 7, 603-618. 
Strenger, C. (1998). Individuality, the impossible project: Psychoanalysis and self creation. Madison, CT: International Universities Press.

Sullivan, H. S. (1953). The Interpersonal Theory of Psychiatry. New York: W. W. Norton.

Tomkins, S. (1962). Affect, imagery and consciousness. New York: Springer.

Winnicott, D. W. (1945). Primitive emotional development. In: Trough Pediatrics to psychoanalysis, NY: Basic Books, 1975, pp. 145-156.

Winnicott, D. W. (1952/1975). Psychosis and child care. In : D. Winnicott (Ed.), Trough Pediatrics to psychoanalysis (pp. 219-228.) NY: Basic Books.

Winnicott, D. W. (1960/1965). Ego distortion in terms of true and false self. In D. Winnicott (Ed.), The maturational processes and the facilitating environment (pp. 140-152). New York: International Universities Press

Winnicott, D. W. (1965). The maturational processes and the facilitating environment. New York, NY: International Universities Press.

Winnicott, D. W. (1971a). Playing and reality. London, UK: Routledge.

Winnicott, D. W. (1983). A capacidade para estar só. In D. Winnicott (Ed.), O ambiente e os processos de maturação (pp.31-37) Porto Alegre: Artes Médicas.

Original recibido con fecha: 1/12/2020 Revisado: 15/4/2021 Aceptado: 30/09/2021 